\title{
A NEW-FANGLED CONTROLLING STRUCTURE FOR MITIGATING VOLTAGE SAG USING THE DVR
}

\author{
B. Durai Babu ${ }^{1}$, Dr.P.Murugesan ${ }^{2}$ \\ ${ }^{1}$ Research Scholar, Department of Electrical Engineering, Sathyabama University, Chennai, Tamil Nadu 600119, \\ India \\ .$^{2}$ Professor, Department of Electrical and Electronics Engineering, S.A. Engineering College, Chennai, Tamil \\ Nadu, India. \\ duraibabu17@yahoo.com
}

\begin{abstract}
Voltage mitigation in electrical power circulation systems is unique of the crucial errands in recent days, which affects the overall presentation of the distribution system. The voltage sag must be detected and mitigated by implementing a Dynamic Voltage Restorer (DVR). The current works aimed to develop some controlling structures for reducing the voltage sag in the power system. Still, it remains with increased transients, incapability to compensate the mark voltage, and increased voltage limits. Thus, this paper intends to develop a new controlling algorithm, namely, Synchronous Reference Theory (SRF), for voltage sag mitigation. This Controller's primary considerations are to moderate the voltage sag, analyze the imbalance cutting-edge source voltage, and reduce the harmonic content. Here, the 3-phase load current obtained from the non-mark ar load is given as the input, which is transformed into dq0 reference. The DC quantities are extracted and presented as the input for the extraordinary pass purifyingmethod, eliminating the vocal contents. Then, the SRF controller produces the switching pulses for the Z-source inverter, which reduces the voltage sag. Finally, the presentation of the Controller is evaluated by analyzing the power ingesting and effectiveness.
\end{abstract}

keywords-Dynamic Voltage Restorer (DVR), Power Distribution System, Voltage Sag Mitigation, Z- Home Inverter (ZSI), Controller, and Pulse Width Modulation (PWM).

\section{Introduction}

Dynamic Voltage Restorer (DVR) is a kind of power device used in many control system applications to solve the problems of voltage sag and swell.It is a compensator that is widely used torecuperate the power quality condition[1]. The distribution system is installed between the critical load feeder and power supply unit[2]. Naturally, the DVR is a kind of electronic device that contains an inverter, energy storage device, and filter components. It continually monitors the load voltage waveforms by injecting the missing voltages[3]. Also, it can compensate for any disturbances that affect the load voltage.In DVR[4], 3 modes of operations are performed:defense mode, standinmethod, and injection method. There are altered controlling plans used to control the DVR for improving the power quality of distribution systems[5]. It includes mark ar control and non-mark ar control strategies, in which mark ar control is

Copyright $($ ) Authors

considered the common rule used in DVR. The DVR[6] is regarded then asa non-mark ar device due to semiconductor switches' usage. When compared to the non-mark ar controls, the mark arrule requires less computational effort[7]. These controlling strategies highly depend on the load characteristics; based on this, the compensation methods [8]are classified into the following types:

- Pre-sag compensation

- Voltage tolerance

- In-phase compensation

- In-phase advanced compensation 


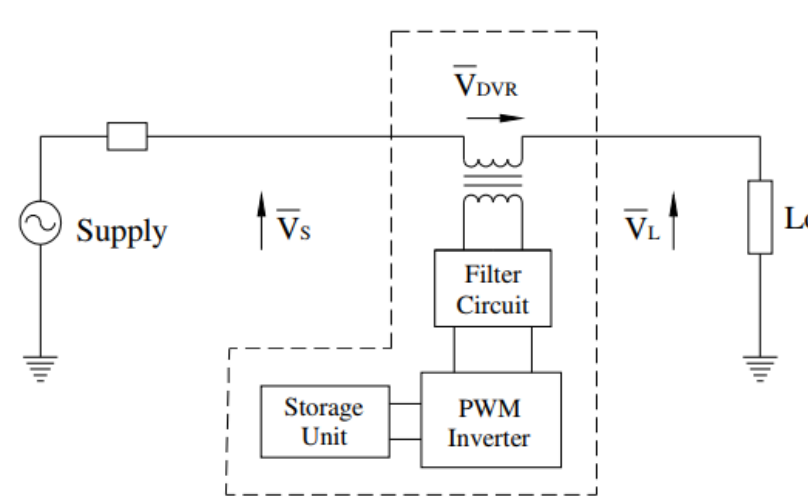

Fig 1. Schematic diagram of DVR

\section{A. Problem Identification}

Reducing the voltage sag and swell significantly contributes to designing the distributed power system[9]. Usually, the DVR is developed for reducing the voltage fluctuations with increased efficiency[10]. During the design of ZSI, the following features must be considered: the DC-AC power conversion is performed to obtain the required A.C. voltage[11].It efficiently suppressed the voltage by using the high pass filtering technique.Due to the action of an inductor, the harmonics in the current are reduced. Many controlling algorithms and circuit topologies are developed in the traditional works for lowering both the voltage sag and swell[12]. But, it has some significant limitations such as:

- Increased transients in voltage

- It failed to compensate the mark voltage harmonics

- It is not capable of handling the active power flow

- Increased voltage limits

This study aims to solve these concerns and develop a new controlling design by using the ZSI.

\section{B. Objectives}

The primary objectives of this paper are as follows:

To efficiently decrease the voltage sag and swell in the distribution system, a new controlling topology, namely, Synchronous Reference Frame Theory (SRF) is developed.

- To remove the harmonic distortion in the output voltage, the high pass filtering technique is implemented.

- To convert the 3-phase voltage current into the $\mathrm{d}-\mathrm{q}-0$ reference, the DQ0 transformation technique is implemented.
- To produce the pulses for ZSI, the Sinusoidal Pulse Width Modulation (SPWM) technique is utilized.

\section{Organization}

The rest of the paper sections are structured as follows: the existing structures and Simulink models used for designing the DVR are investigated with their advantages and disadvantages in Section II. A detailed description of the proposed DVR modeling with the Simulink prototypical is obtainable in Section III. The simulation results of both existing and proposed models are validated by using various parameters in Section IV. Lastly, the overall instant of the paper is concluded with its future enhancement in Section V.

\section{Related Works}

Galeshi and Iman-Eini[13] designed a multilevel flowed H-bridge inverter for Dynamic Voltage Restorer (DVR). The paper intended to eliminate series injection transformer by directly connecting DVR to the medium voltage networks. The zero-energy compensation method was also implemented to reduce the voltage sag and delay of the DVR systems. Moreover, this scheme contains 3 separate controllers, maintaining the voltage balance between the D.C. link capacitors. Sundarabalan and Selvi[14] implemented a Proton Exchange Membrane Fuel Cell (PEMFC) stack for optimizing the parameters used for the P.I. controller. It was used as a solid polymer electrolyte for the preoccupation of protons and refusal of electrons. In this design, the hydrogen molecules were divided into electrons and protons by using the platinum catalyst. Here, a fuel cell stack was formed by grouping the fuel cells together. Moreover, the tournament selection algorithm was utilized, in which two solutions were randomly selected from the population.

Carlos, et al[15]suggested a complete control system using a Pulse Width Modulation (PWM) technique for 3-phase four-wire systems. Here, two types of power distribution systems were considered:3 Phase 3 Wire (3P3W) and 3 Phase Four Wire (3P4W). This system considered the following criterion:summary harmonic distortion, little electromagnetic interference, and extraordinary voltage procedure capability. Rauf and Khadkikar[16] utilized an enhanced voltage sag compensation mechanism for DVR, aiming to reduce the phase jump in the load voltage. In this paper, the overview ofDVR operations was stated, which includes in-phase compensation, quadrature injection, energy-optimized injection, and presage compensation. In the suggested scheme, the amount of active power injected by DVR was regulated by optimizing the D.C. link voltage gradient. The 
advantage of this mechanism was, it improved the voltage quality of sensitive loads with reduced compensation time. Jowder[17] developed a voltage sag and harmonics detection mechanism for designing the DAR. This control system was entirely based on the hysteresis voltage control, in which the load voltage was compensated by increasing the power quality. In this circuit, the step-up dc-to-dc motor was integrated to maintain and control the inverter's D.C. voltage. Also, the Proportional Integral (P.I.) The Controller was used to produce the suitable duty cycle, and the uncontrolled rectifier was connected with the load bus via a step down transformer. Moreover, the harmonic components were extracted from different waveforms such as phase A, phase B, and phase C. From the paper, it was analyzed that the time domain simulations must be performed to prove the performance of voltage sag compensation method.

Vilathgamuwa, et al [18] implemented a new Phase Advance Compensation (PAC) for enhancing the property of voltage restoration. This mechanism focused on the following contributions:

- A more compact system was designed by reducing the amount of stored energy.

- The magnitude of the injected voltage was reduced.

- The reactive power supply was improved based on the advanced angle and sag.

Usually, the DVR's fidelityhighly depended on the dynamic behavior and accuracy of the voltage synthesis and control system. Parreño et al[19]developed a two Degrees of Freedom (2DOF) resonant control scheme for attaining both a balanced and unbalanced voltage sag compensation. Here, the design procedure was focused on selecting the dominant poles of the closed-loop system, which reduced the number of required design parameters. Here, it was stated that the components at the fundamental frequency could be tracked for accomplishing the requirements of voltage sag compensation. Shahabadini and Iman-Eini[20] designed a new device, namely, Intermark Dynamic Voltage Restorer (IDVR), for voltage sag extenuation. In this design, two cascaded H-bridge multilevel converters were utilized to inject the A.C. voltage with reduced total harmonics distortion. Based on the required A.C. voltage and voltage ratings, the number of $\mathrm{H}$-bridge cells was selected. Here, the compensation capacity of IDVR was improved and the deep sags were mitigated at varying high power factors. When the voltage sag was detected, the source voltages were continuously sensed and the load power factors were reduced.
Jothibasu and Mithra[24] suggested a control scheme based on voltage sags' characterizationfor addressing the voltage related P.W. problems. This mechanism integrated the functionalities of symmetrical component theory and Fourier transform for extracting the fundamental symmetrical components. The efficiency of this algorithm was tested by simulating the asymmetrical and symmetrical sags. Jayaprakash et al.[25] analyzed various voltage injection schemes for battery energy storage systems. Here, a reduced rating DVR was utilized to compensate for the voltage sag, harmonics, and swell. The voltage sags were balanced with the use of DVR by injecting or absorbing real power and reactive power. In this design, two P.I. controllers were utilized to estimate the error between the reference and actual DVR. Moreover, the DVR connected system contains the components of a series injection transformer, 3-phase critical loads, and 3phase supply. Akbari, et al.[26] introduced a Modular Multilevel Cascade Converter - Double Star Chopper Cell (MMCC-DSCC) for the voltage sag and swelled compensation. In this design, the switching pattern of the Phase Shift Multi-Carrier Modulation (PSHM) scheme was extracted during the voltage sag compensation. In this controlling strategy, the size and angle of voltage were estimated concerning varying voltage disturbances. The benefits of MMCC were as follows:

- Increased efficiency and reliability

- Low voltage stress

- Modular structure and flexible

However, it required to select an appropriate modulation system for balancing the inverter control voltage per cell. Babaei and Kangarlu[27] compared four different topologies for 3-phase DVR to improve the voltage related power quality. In this design, each phase's inverter was independently operated and controlled for balancing the voltage sags and swells. This DVR utilized a reduced number of switching devices for the H-bridge inverters. This paper analyzed 3 different compensation strategies: pre-sag, in-phase, and minimum active power injection methods. Suresh and Baskaran[28] modeled a closed-loop P.I., PID, and F.L. controlled system for performing the voltage sag compensation. Here, the Intermark Dynamic Voltage Restorer (IDVR) was utilized to model and simulate the sag compensation. Typically, the voltage sag was depended on various issues such as fault present, modifier in the propagation path, voltage level, and connection arrangement.

From the survey, it is investigated that the existing designing structures have both advantages and 
disadvantages, but it mainly lacks with the following limitations:

- Maximum injection capability

- Increased compensation time

- Voltage, current, and power limit

- Incapable of handling the voltage disturbance This work aims to develop a new controlling scheme usingDVR for compensating the voltage sags with increased efficiency to resolve these complications.

\section{Proposed Methodology}

This section presents a detailed description of the proposed DVR system with its clear flow and Simulink illustrations. This paper's main intention is to reduce the voltage sag and swell by designing the new Controller, namely, Synchronous Reference Frame (SRF) theory. In this design, the DVR is linkedamid the grid and the no-mark ar load. The critical role of DVR is to detect the occurrence of voltage sag by generating the trigger pulses for compensation. The operational flow of this system is shown in Fig 1, in which the power from the grid is analyzed based on the 3-phase load current. Then, the D.C. quantities are estimated by using the DQ0 transformation technique, and the high pass filtering technique is used to filter the amounts. After that, the SPWM generates the pulses for the z-source inverter, given the non-mark ar load connected with the grid. Finally, the voltage sag mitigation of DVR is analyzed by evaluating the power consumption and efficiency measures.

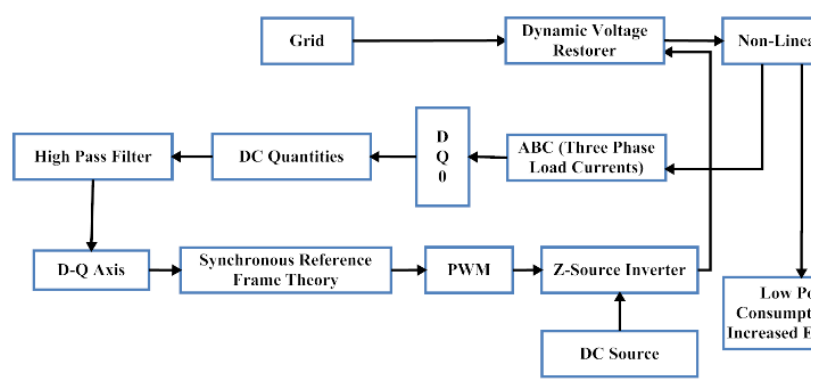

Fig 2. Flow of the proposed DVR system

\section{Control Scheme}

In this paper, an SRF theory-based controller technique is implemented to mitigate the voltage sag. In this design, the voltage sag is compensated by injecting the real or reactive power using the DVR. Typically, the DVR is self-supported with the D.C. bus, in which the compensation is attained based on the injected voltage and fundamental frequency. Moreover, this controlling technique can solve the problems like voltage injection capability and energy storage size optimization. The DVR dynamically injects the controlled voltage that isproduced by the converter. Naturally, the DVR can be measured by using the Fourier transform, PLL, wavelet transform, and peak value detection methods. The primary responsibilities of this Controller are as follows: (i) to find the voltage sag in the systems, (ii) to compute the correct voltage, and (iii) to generate the trigger pulses. Also, it analyzes the sag depth and updates the phase shift information at the starting and ending times. The DVR injects the reactive power to compensate for the small disturbances and inject the real energy for paying the considerable troubles. Moreover, the control unit gives the required voltage that needs to be inserted during voltage sag. The SPWM is used to control the DVR by using the sold state power electronic switching devices.

The working procedure of this controller design is illustrated as follows:

- At first, the abc reference frame's voltage is converted into the dq0 reference, which reduces the complexity of zero phase sequence components.

- The DVR is controlled based on the reference voltage and measured terminal voltage $\left(V_{a}, V_{b}, V_{c}\right)$

- When the supply is below $90 \%$ of the reference value, the voltage sag can be detected.

- Here, the reference signal acts like aninterjecting signal, which creates the commutation pattern for the power switches, and the sinusoidal pulse width modulation makes it.

- Moreover, the factors such as load inductance, load resistance, mark frequency, filter inductance, filter capacitance, dc bus voltage, and series transformer turn ratio, primary voltage per phase, and mark impedance are adjusted for detecting the voltage sag. 


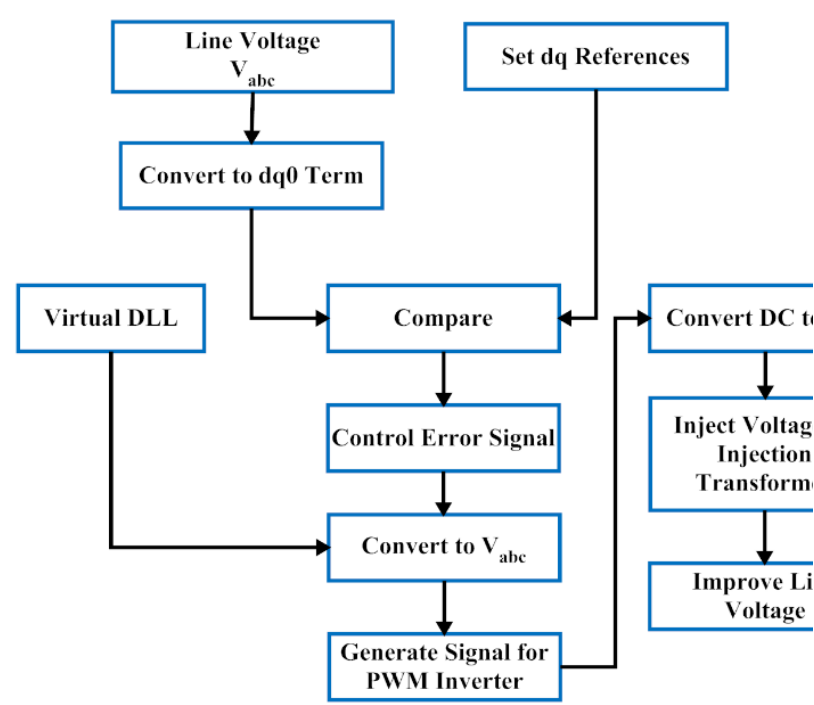

Fig 3. Controller structure

\section{E. DQ0 Transformation}

This transformation technique is mainly used to control the DVR by analyzing the sag depth. In this technique, the quantities are estimated based on the direct space vectors. Here, the voltage obtained from the non-mark ar load is converted into the DQ0 reference. Then, the voltage reference and the terminal voltage are compared for detecting the voltage sag. If the voltage supply is below $90 \%$ of the reference voltage, it is seen as voltage sag, and if the supply voltage is increased up to $25 \%$ of the reference voltage, it is detected as the voltage swell. Here, the dq0 transformation, also known as a park transform, is utilized, which changes the stationary phase coordinate system (ABC) to a rotating coordinate system (dq0). The controlling technique reduces the total harmonic distortion with reduced period-variable inductance of the switching voltage based on this procedure. Moreover, it productsdiversesprouts through time, orientation voltage, and phase angle to precisely invert the input D.C. voltage hooked on A.C. voltage.

\section{F. Filtering}

The voltage sags lead to be the fault, which must be rectified in the transmission or distribution system. The filtering scheme is mainly applied to maintain the harmonic distortion of the voltage at the load side. Thus, the high pass filtering technique is used in this paper to eliminate the harmonics and oscillatory components of the voltage.This filtering technique maintains the harmonic content at the permissible level. In this technique, the capacitor acts similar an open circuit because the capacitor's reactance is very high. The DVR is entirely founded on the cascaded $\mathrm{H}$-bridge circuit, in which the capacitor value of the filter is estimated based on the resonant frequency.

\section{G. Sinusoidal Pulse Width Modulation}

Due to the high modulation index and lower harmonics distortion, the SPWM is widely used in many application areas. It generates the sinusoidal pulses for controlling the shoot-through time in the ZSI. Based on the operating modes and different directions of the switching voltages, the switching pattern is analyzed. The dead time is estimated based on the alterationamong the time occupied for the two switching processes. Using this technique, the output voltage is boosted, and the settling level is reduced during the switches' conduction period. Moreover, the output waveform is obtained for finding the shootthrough states.

\section{H. Z-Source Inverter}

The Z-home inverter (ZSI) plays aimportant role in providing the A.C. output voltage by the appropriategenerating of switches.

The Z-source inverter's primary role is converting D.C. signal to A.C.indicationdeprived ofaobligation of the extra DC-DC converter. In this paper, the highefficient $\mathrm{Z}$-source inverter is designed to meet the desired needs and regulate the D.C. input with reduced harmonic distortion.Typically, the z-source inverter can be operated at varying modes, including normal mode, active method, and sprout through mode. The sprout-through method is selected because it secures voltage increase or decrease in a single step energy processing. It has the following benefits: improvement in power factor, reduction in harmonic current, standard mode voltage, and any additional circuit. The shoot-through time can be increased based on the capacitor voltage. The capacitor voltage is matching to the middling of the D.C.connection voltage diagonally the inverter conduit due to consuming a 0 value for anmiddling of inductor voltage. 


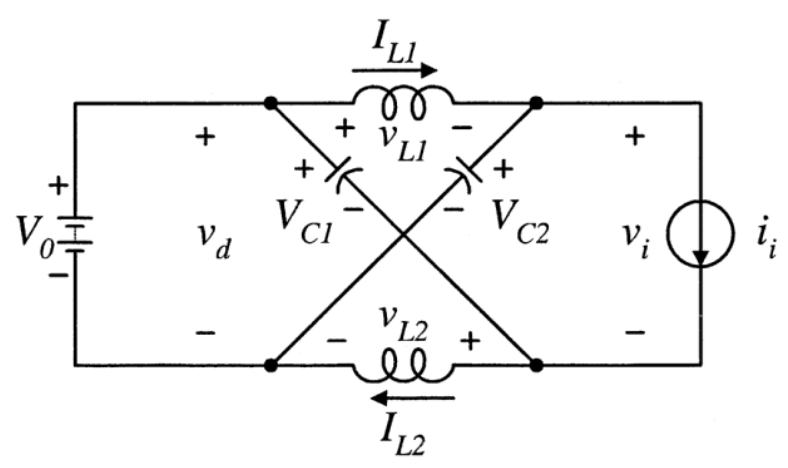

Fig 4. Z-Source Inverter

Let consider the capacitors $\left(C_{1}, C_{2}\right)$ and inductors $\left(L_{1}, L_{2}\right)$ have the same value to make the $\mathrm{z}$-source inverter as symmetrical,

$L=L 1+L 2$

$$
\begin{aligned}
& C=C 1+C 2 \\
& V=V 1+V 2 \\
& C_{V}=C_{1 V}+C_{2 V}
\end{aligned}
$$

Where $\mathrm{V}$ is the instantaneous voltage across the inductor and $\mathrm{C}_{\mathrm{v}}$ is the capacitor voltage. The Z-home inverter is functioning in the sprout-finishedmethod for an recessof $T_{0}$, in which two switches of any one phase of any 2steps are directing at this period. Based on these conditions, the circuit is represented by the following equations:

$V=C_{V}$

$V_{d c}=2 C_{V}$

$V_{\text {dcavg }}=0$

(7)

Where, $V_{d c}$ represents the input dc voltage and

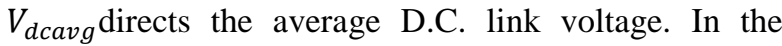
switching cycle $\mathrm{T}$, the inverter is operating in active states for the interval of $\mathrm{T} 1$.

$V=V_{s}-C_{V}$

$V_{d c}=V_{s}$

(9)

\section{Copyright $($ ) Authors}

$V_{\text {dcavg }}=C_{V}-V=2 C_{V}-V_{s}$

(10)

Where, $V_{S}$ represents the D.C.basis voltage and $T=$ $T 0+T 1$. In steady-state, the regular voltage of the inductors over one swappingdated $\mathrm{T}$ must be zero, which is shown in the following equations:

$T 0 \times C_{V}+T 1 \times\left(V_{s}-C_{V}\right)=0$

$\frac{C_{v}}{V_{s}}=T 1 /(T 1-T 0)$

The capacitor voltage of the Z-source inverter is determined as follows:

$C_{V}=T-T 0(T-T 0-T 0) \times V_{S}$

$C_{V}=1-(T 0 / T) 1-(2 T 0-T) \times V_{S}$

The average D.C. link voltage is represented as follows:

$v_{\text {dcavg }}=C_{V}-V 1=2 C_{V}-V_{s}=\frac{T}{T 1-T 0} \times V_{s}=b_{f} \times V_{s}$

Where, $b_{f}$ represents the boosting factor,

$b_{f}=T(T 1-T 0)$

(16)

The peak phase voltage from the inverter is written as follows:

$V_{a c}=m_{i} \times V_{\text {dcavg }} / 2$

Where, $m_{i}$ represents the modulation index of the $\mathrm{z}$ source inverter.

$V_{a c}=m_{i} \times b_{f} \times\left(V_{s} / 2\right)$

(18)

From these calculations, it is observed that the output voltage can be treaded up or treaded down by selecting the correct values of the modulation index and boosting factor $b_{f}$, which is measured by using the responsibility cycle of the sprout-through state of the inverter.

\section{Performance0 Analysis}

This section, the future SRF controller design's simulation results are evaluated using various parameters, including phase voltage, phase current, 
filtering outputs, and triggered pulses. The simulation specifications of this design are illustrated in Table 1.

Table 1. Simulation specifications

\begin{tabular}{|l|l|}
\hline Parameters & Values \\
\hline Input voltage & $700 \mathrm{~V}$ \\
\hline Output voltage & $300 \mathrm{~V}$ \\
\hline Inductor & $\mathrm{L} 1=75 \mathrm{mH}, \mathrm{L} 2=75 \mathrm{mH}$ \\
\hline Capacitor & $\mathrm{C} 1=750 \mu \mathrm{f}, \mathrm{C} 2=750 \mu \mathrm{f}$ \\
\hline Load resistance & $60 \mathrm{ohms}$ \\
\hline Load inductance & $0.15 \mathrm{mH}$ \\
\hline Nominal power & $4000 \mathrm{VA}$ \\
\hline Nominal frequency & $50 \mathrm{~Hz}$ \\
\hline
\end{tabular}

\section{3- Phase Output Voltage at Grid Side}

Fig 5 shows the 3-phase output energyonthe grid side, in which the yellow color markdirects phase A, the pink color mark directsphase $\mathrm{B}$, and the blue color mark directs phase $\mathrm{C}$. The frequency and phase angle of the sinusoidal wave is estimated by using the sinusoidal measurement. The sinusoid of the 3-phase output is generated in the form of,

$s(t)=A_{m}(t) \sin \left(\emptyset_{0}+\int 2 \pi f(t) d t\right)$

(19)

Wheres(t) represents the estimate of the input signal, $A_{m}$ directs the amplitude of the input signal, and $\emptyset_{0}$ denotes the initial phase angle.

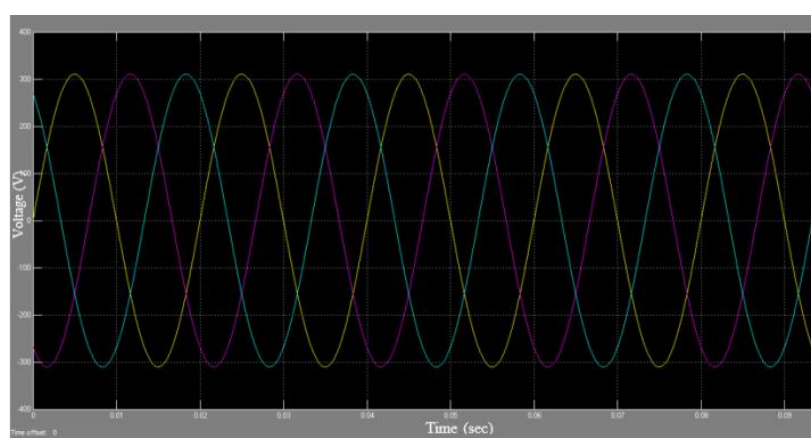

Fig 5. 3-phase production voltage at the grid side

\section{J. Filter Outputs (D.C. Components)}

The 3-phase voltage (ABC) acquiredsince the nonmark arcapacity is transformedhooked on the dq0 orientations by smearing the dq0 alterationmethod. Formerly, the D.C.amounts are projectedafter the dq0 alteration, and it is given to the extraordinary pass purifyingmethod that decreases the vocalsubjects. The strainedproductivities of the D.C.mechanisms for phase A, phase B, and phase $\mathrm{C}$ are signified in Fig 6 to Fig 8 .

Copyright (C) Authors

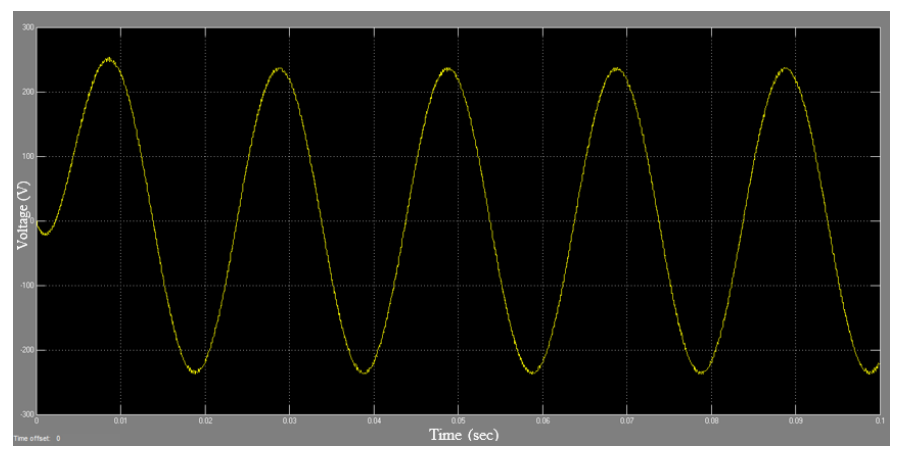

Fig 6. The filtered output of phase A

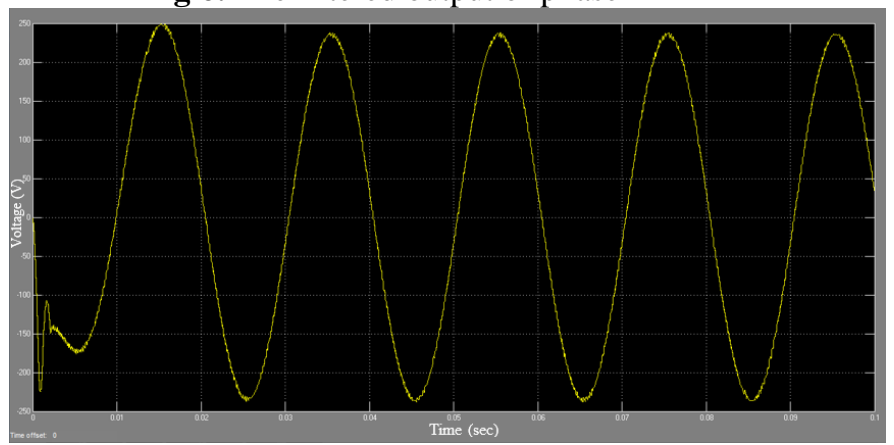

Fig 7. The filtered output of phase B

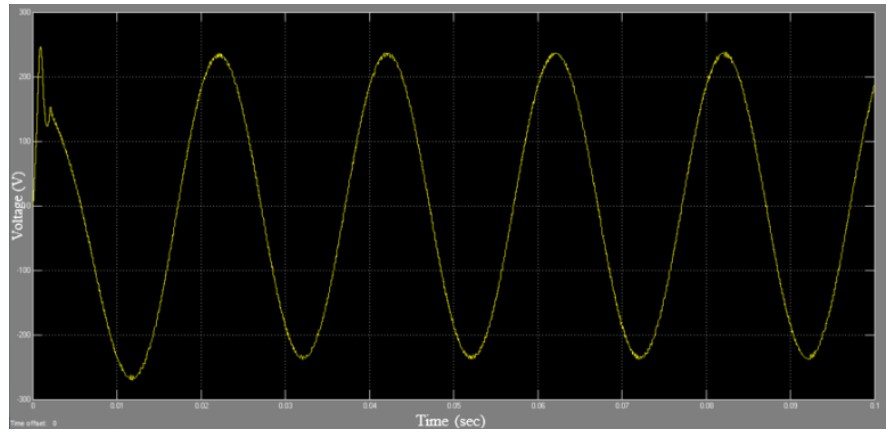

Fig 8. The filtered output of phase $\mathrm{C}$

K. Load Side 3-Phase Output Voltage

Laterproducing the pulses for the inverter, the 3phase capacity electricity is given to the non-mark arcapacity, as shown in Fig 9. The yellow color markdirects phase $\mathrm{A}$, the pink color directs phase B, and the blue color directs phase C. Formerly, the output voltages' phase-amplitude is continuedas endless for respectively phase byinvestigating the penetration of voltage sag. 


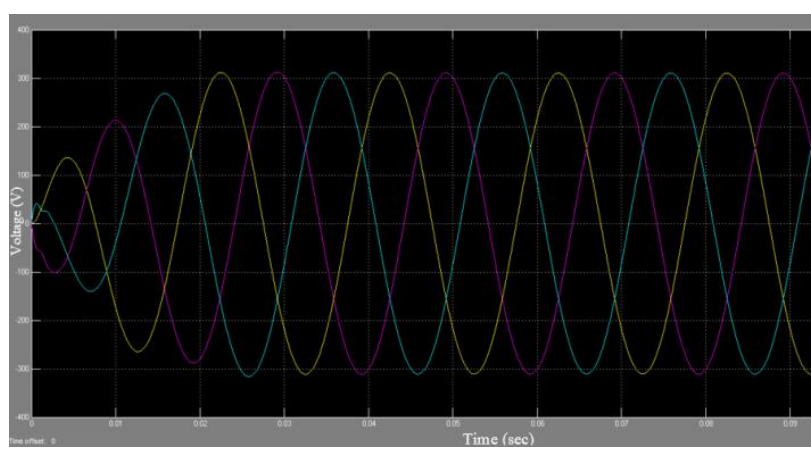

Fig 9. 3 output voltage at the load side

\section{SPWM Pulse Generated3-Phase Output Voltage at ZSI}

Here, the SPWM generates the pulsates for the ZSI by using the SRF theory-based Controller. The pulse triggered 3 output voltage at the inverter side is shown in Fig 10.The SPWM controls the 3 phase inverter's switching behavior based on the following: 3 sinusoidal reference voltages, D.C. link voltage, and D.C. link neutral point.

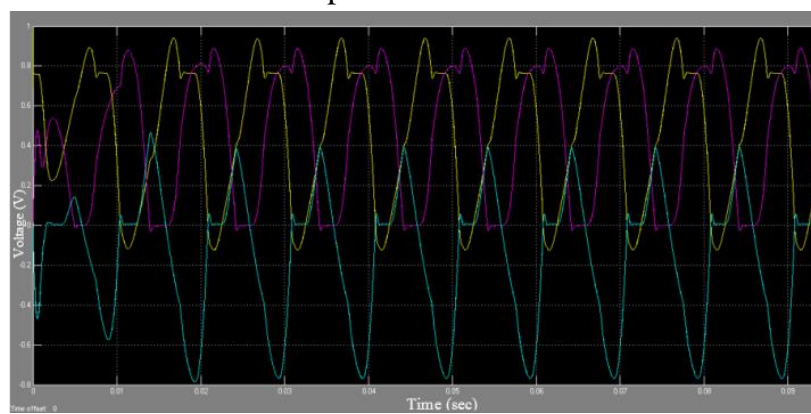

Fig 10. SPWM generated pulses at inverter side

\section{Comparative Analysis}

Table 2 compares the existing open-loop Controller and proposed SRF theory controller concerning the various measures. It includes phase voltage, phase current, V.A. per phase, \% of load, supply current, and load voltage. In the existing openloop Controller, the measures are estimated based on the values of supply-side voltage and a reference voltage. In the proposed Controller, the measurements are calculated based on the reference load voltage and actual voltage. From the evaluation, it is observed that the proposed SRF theory-based controller design provides better results compared to the existing Controller.

Table 2. Comparative analysis of existing and proposed controller designs

\begin{tabular}{|l|l|l|}
\hline Parameters & $\begin{array}{l}\text { Open-loop } \\
\text { Controller }\end{array}$ & $\begin{array}{l}\text { SRF theory } \\
\text { controller }\end{array}$ \\
\hline $\begin{array}{l}\text { Phase voltage } \\
\text { (V) }\end{array}$ & 100 & 135 \\
\hline
\end{tabular}

\begin{tabular}{|l|l|l|}
\hline $\begin{array}{l}\text { Phase current } \\
(\mathrm{A})\end{array}$ & 18 & 18 \\
\hline V.A. per phase & 1800 & 2430 \\
\hline $\begin{array}{l}\text { KVA (\% of } \\
\text { load) }\end{array}$ & $43.25 \%$ & $58.65 \%$ \\
\hline $\begin{array}{l}\text { Supply current } \\
\text { (A) }\end{array}$ & 22.15 & 20.12 \\
\hline $\begin{array}{l}\text { Load voltage } \\
\text { (V) }\end{array}$ & 380.8 & 410.8 \\
\hline
\end{tabular}

\section{Conclusion and Future Work}

This paper aims to develop a new controlling scheme aimed atjustifying the voltage sag in authority distribution schemes. For this purpose, the concept of SRF theory, dq0 transformation, and ZSI is used in this work. With this integration, the DVR can compensate for the voltage sag without requiring any additional components. At first, the 3-phase capacityflows obtained from the non-mark ar load is transformed into dq0 references. Then, the D.C. quantities are estimated from the connections certain to the extraordinarypermitpurifyingmethod for reducing harmonics.

Consequently, the SPWM is utilized to generate the triggered pulses for the ZSI, and the output load currents are given to the non-mark ar load. Finally, the power consumption and energy efficiency of this Controller are estimated by using various performance measures. During the simulation, the phase current, phase voltage, supply current, and load voltage are calculated. Then, the results of the planned SRF theory regulator is matched with the existing open-loop Controller. The results show that the proposed regulator technique outperforms the other method by efficiently mitigating the voltage sags.

In the future, this work can be enhanced by implementing this controller scheme in the scatteredsupremacygroup system to attain better grid regulator and harmonization when the regular and lop-sided faults are produced.

\section{REFERENCES}

[1] A. M. Saeed, et al., "Power conditioning using dynamic voltage restorers under different voltage sag types," Journal of advanced research, vol. 7, pp. 95-103, 2016.

[2] S. S. Kishore, et al., "Voltage sag reduction and power quality improvement using DVR," in Computation of Power, Energy Information 
and Communication (ICCPEIC), 2017 International Conference on, 2017, pp. 761767.

[3] H. Abdollahzadeh, et al., "A new fastconverged estimation approach for Dynamic Voltage Restorer (DVR) to compensate voltage sags in waveform distortion conditions," International Journal of Electrical Power \& Energy Systems, vol. 54, pp. 598-609, 2014.

[4] E. Babaei, et al., "Compensation of voltage sags and swells using photovoltaic source based DVR," in Electrical Engineering/Electronics, Computer, Telecommunications and Information Technology (ECTI-CON), 2017 14th International Conference on, 2017, pp. 903906.

[5] B. V. Rao, et al., "PEMFC Based Z-Source DVR for Voltage Sag/Swell compensation and Active/Reactive Power Analysis," Journal of Controller and Converters, vol. 2, 2017.

[6] D. Somayajula and M. L. Crow, "An integrated dynamic voltage restorer-ultracapacitor design for improving power quality of the distribution grid," IEEE Transactions on Sustainable Energy, vol. 6, pp. 616-624, 2015.

[7] M. Chaudhari and N. Joshi, "MITIGATION OF VOLTAGE SAG BY USING SINGLE PHASE DYNAMIC VOLTAGE RESTORER," Development, vol. 2, 2015.

[8] B. P. Ganthia, et al., "Compensation of voltage sag using DVR with P.I. controller," in Electrical, Electronics, and Optimization Techniques (ICEEOT), International Conference on, 2016, pp. 2138-2142.

[9] R. Pal and S. Gupta, "Simulation of dynamic voltage restorer (DVR) to mitigate voltage sag during 3-phase fault," in Electrical Power and Energy Systems (ICEPES), International Conference on, 2016, pp. 105-110.

[10] B. Wang, et al., "A DC microgrid integrated dynamic voltage restorer with model predictive control," in Energy, Power and Transportation Electrification (ACEPT), 2017 Asian Conference on, 2017, pp. 1-5.

[11] M. M. Far, et al., "Power capacity management of dynamic voltage restorers used for voltage sag and unbalance compensation," in Universities Power Engineering Conference (AUPEC), 2017 Australasian, 2017, pp. 1-6.

[12] N. Muluk, et al., "Voltage sag mitigation due to short circuit current using dynamic voltage restorer based on hysteresis controller," in Information Technology, Computer, and Electrical Engineering (ICITACEE), 2017 4th International Conference on, 2017, pp. 108112.
[13] S. Galeshi and H. Iman-Eini, "Dynamic voltage restorer employing multilevel cascaded $\mathrm{H}$ bridge inverter," IET Power Electronics, vol. 9 , pp. 2196-2204, 2016.

[14] C. Sundarabalan and K. Selvi, "Compensation of voltage disturbances using PEMFC supported Dynamic Voltage Restorer," International Journal of Electrical Power \& Energy Systems, vol. 71, pp. 77-92, 2015.

[15] G. A. de Almeida Carlos, et al., "Investigation on dynamic voltage restorers with two de links and series converters for 3-phase four-wire systems," IEEE Transactions on Industry Applications, vol. 52, pp. 1608-1620, 2016.

[16] A. M. Rauf and V. Khadkikar, "An enhanced voltage sag compensation scheme for dynamic voltage restorer," IEEE transactions on industrial electronics, vol. 62, pp. 2683-2692, 2015.

[17] F. Jowder, "Design and analysis of dynamic voltage restorer for deep voltage sag and harmonic compensation," IET generation, transmission \& distribution, vol. 3, pp. 547560, 2009.

[18] D. Vilathgamuwa, et al., "Voltage Sag Compensation with Energy Optimized Dynamic Voltage Restorer," IEEE Power Engineering Review, vol. 22, pp. 63-63, 2002.

[19] A. Parreño, et al., "A Two Degrees of Freedom Resonant Control Scheme for Voltage Sag Compensation in Dynamic Voltage Restorers," IEEE Transactions on Power Electronics, 2017.

Copyright O Authors

ISSN (Print): 2204-0595

ISSN (Online): 2203-1731 